This item was submitted to Loughborough's Research Repository by the author.

Items in Figshare are protected by copyright, with all rights reserved, unless otherwise indicated.

\title{
Better patient-doctor communication - a survey and focus group study
}

PLEASE CITE THE PUBLISHED VERSION

http://dx.doi.org/10.1007/978-3-319-39399-5_6

\section{PUBLISHER}

(c) Springer International Publishing

\section{VERSION}

AM (Accepted Manuscript)

\section{PUBLISHER STATEMENT}

This work is made available according to the conditions of the Creative Commons Attribution-NonCommercialNoDerivatives 4.0 International (CC BY-NC-ND 4.0) licence. Full details of this licence are available at: https://creativecommons.org/licenses/by-nc-nd/4.0/

\section{LICENCE}

CC BY-NC-ND 4.0

\section{REPOSITORY RECORD}

Maguire, Martin. 2019. "Better Patient-doctor Communication - a Survey and Focus Group Study". figshare. https://hdl.handle.net/2134/20802. 


\title{
Better patient-doctor communication - a survey and focus group study
}

\author{
Martin Maguire \\ Loughborough Design School, Loughborough University \\ Leicestershire, LE11 3TU, UK \\ M.C.Maguire@lboro.ac.uk
}

\begin{abstract}
The study explored barriers to effective communication between doctors and patients, and to encourage patients to be more knowledgeable about their health. A survey was conducted with 128 people who commented on the effectiveness of the process of consulting their doctor and rated a number of alternatives to face-to-face consultations. A focus group explored the topics further and a range of possible solutions to address current barriers were suggested. These include: considering alternative methods for GP consultation, providing new systems to give doctors better overviews of the patient population, devising new methods for patients to record information from consultations, use of diagnostic systems in the surgery and meetings or online forums to promote better informed patients.
\end{abstract}

Keywords: Health, Patient, Patient experience, Doctor, General Practitioner (GP), Patient communication, Ease of communication, Healthcare Information Systems.

\section{Introduction}

The demands on healthcare systems worldwide are increasing as populations increase and people live longer. Patient numbers and limitations on doctors' time can restrict the level of in-depth or personalised information that patients can receive. This may relate to different options for treatment or long term management of chronic conditions. Further barriers to successful healthcare are patient's lack of understanding of health conditions, finding out about new treatments, and awareness of on-going support to guide them.

Within the UK, there is a drive for more openness within healthcare, encouraging patient empowerment, integration of medical records and patient-centred care [1]. Issues such as ownership of a person's health records and the ethical procedures of different groups handling medical information are important issues for this development. The rationale for these initiatives is that if patients had more information and understanding of their state of health, they would be able to take better control of their health which would generate better health outcomes, place fewer burdens on health services, and lead to more cost-effective healthcare services. Some authors have discussed how IT can enhance medical provider-patient relationships [2]. 


\section{Methods of study}

In order to explore the topic of better patient-doctor communication, two studies were carried out. Firstly, a focus group was carried out with a group of 5 members of the public in their 50s and 60s. A number of topics were discussed relating to visiting the doctor. The aim was to obtain their views on and to identify and problems they faced. Secondly, a questionnaire survey was administered to a sample of 128 people. The aims of the questionnaire were to obtain patient opinions of online medical information in general, making appointments to see their doctor, and possible methods of communication with their doctor.

\section{$3 \quad$ Results}

\subsection{Survey}

The survey of 128 respondents included 57 males (44.5\%) and 71 females (55.5\%). The age distribution of the sample was 77 people aged 18-29 (60.2\%), 18 people aged $30-49$ (14.1\%) and 33 people aged 50 and over (25.8\%), so the survey was oriented towards younger.

In terms of accessing medical information when experiencing medical symptoms, it was found that $46.9 \%$ of respondents go online to seek information before consulting their doctor, 38.3\% make an appointment first, while others $(11.7 \%)$ do both at the same time (Fig. 1). One of the reasons that many people go online to find medical information is the ease and immediacy of accessing information from the Internet. This will be situation dependent and as one person said, "If the symptoms were serious or painful I would just make an appointment".

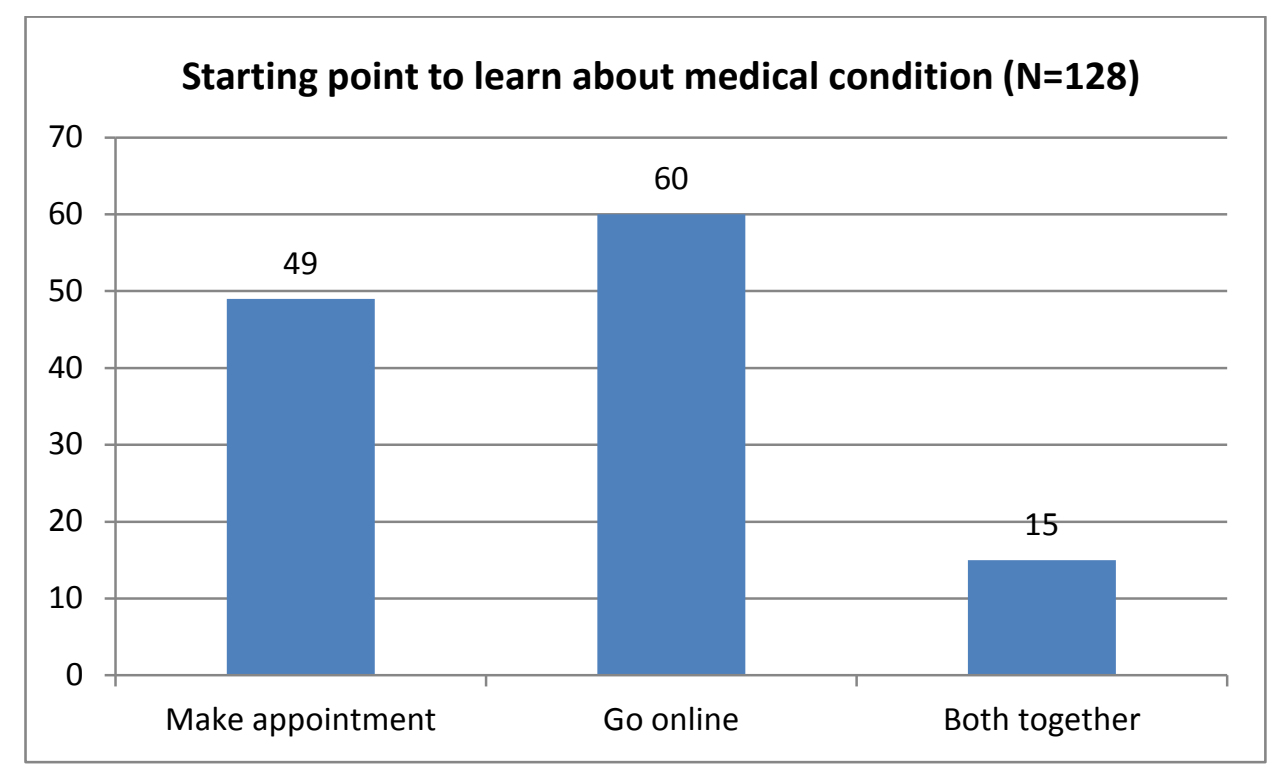

Fig. 1. Survey: Starting point to find out about medical condition 
Respondents were also asked for their opinion of online medical information and how helpful they found it. Their response was recorded on a Likert rating scale. It was found that $45.4 \%$ of people considered it either 'helpful' or 'very helpful' while $30.5 \%$ felt neutral about it. Others were less confident about online medical assistance, with 11\% rating it either 'unhelpful' or 'very unhelpful' (Fig. 2).

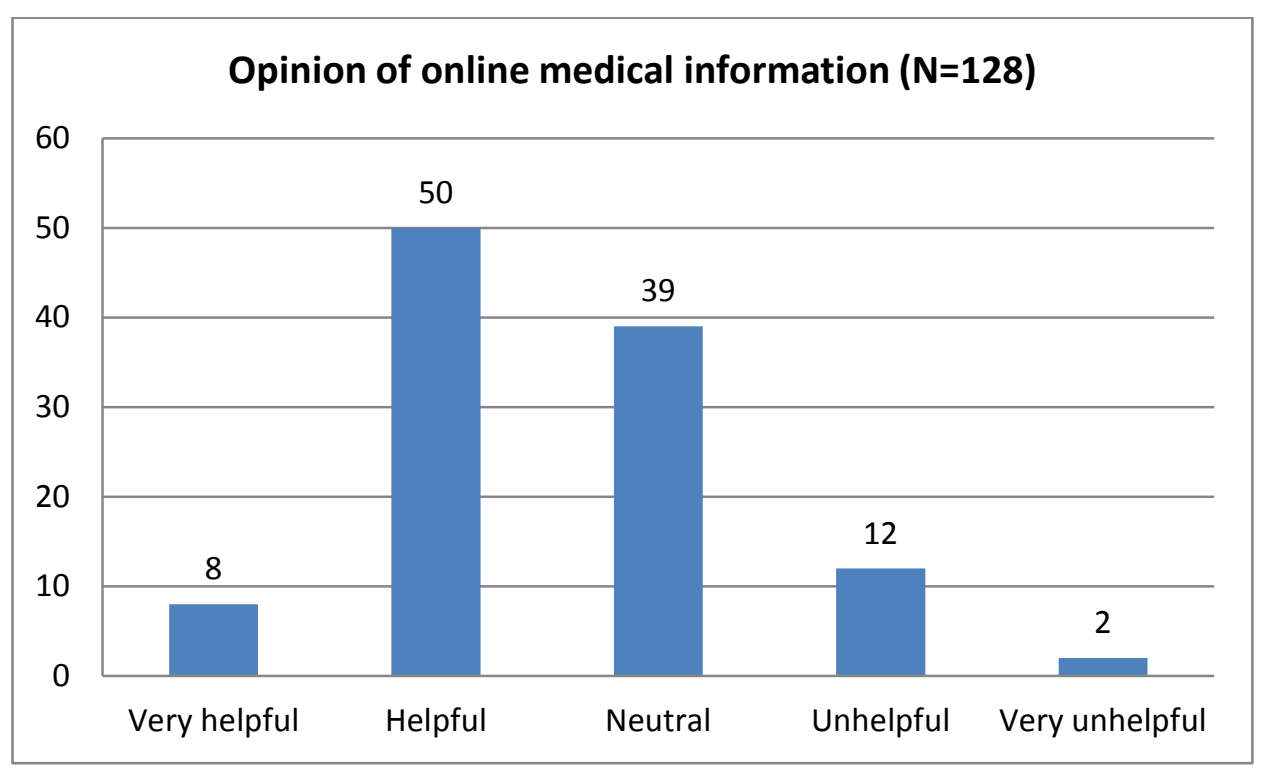

Fig. 2. Survey: Helpfulness of online medical information

Comments were also sought from participants on their experience or opinion of online medical information. Despite the high percentage that rated online information positively, most of the people who commented expressed reservations about the efficacy of this information source. A table of comments and their frequency are shown in Table 1.

Table 1. Comments on online medical information

\begin{tabular}{|lcllc|}
\hline Negative comments & $\begin{array}{l}\text { Fre- } \\
\text { quency }\end{array}$ & Positive comments & $\begin{array}{c}\text { Fre- } \\
\text { quency }\end{array}$ \\
\hline $\begin{array}{l}\text { Not sure how far can trust/may } \\
\text { result in a misdiagnoses. }\end{array}$ & 19 & Gives idea of general medical area. & 5 \\
\hline Often leads to extreme illnesses. & 15 & Saves time/convenience. & 3 \\
\hline Only read from recognised sources. & 8 & Can be really helpful or sage. & 3 \\
\hline $\begin{array}{l}\text { Too many possibilities / inconclu- } \\
\text { sive. }\end{array}$ & 8 & $\begin{array}{l}\text { Useful when GP recommends } \\
\text { specific online information. }\end{array}$ & 1 \\
\hline Not covering all symptoms. & 3 & Useful for the children. & 1 \\
\hline
\end{tabular}


Some people stated that they wouldn't necessarily take their information from a single source but would review a few different websites to look for consistency of information. There was also a requirement for sites to give more information about medications and their possible effects. In a comparison study of 3 online symptom checkers, usability issues were recorded for all 3 systems including relating symptoms to the options provided, the inflexible nature of the process and assuming knowledge that patients did not necessarily have [3]. Bol et al provide advice on medical website design for older patients [4].

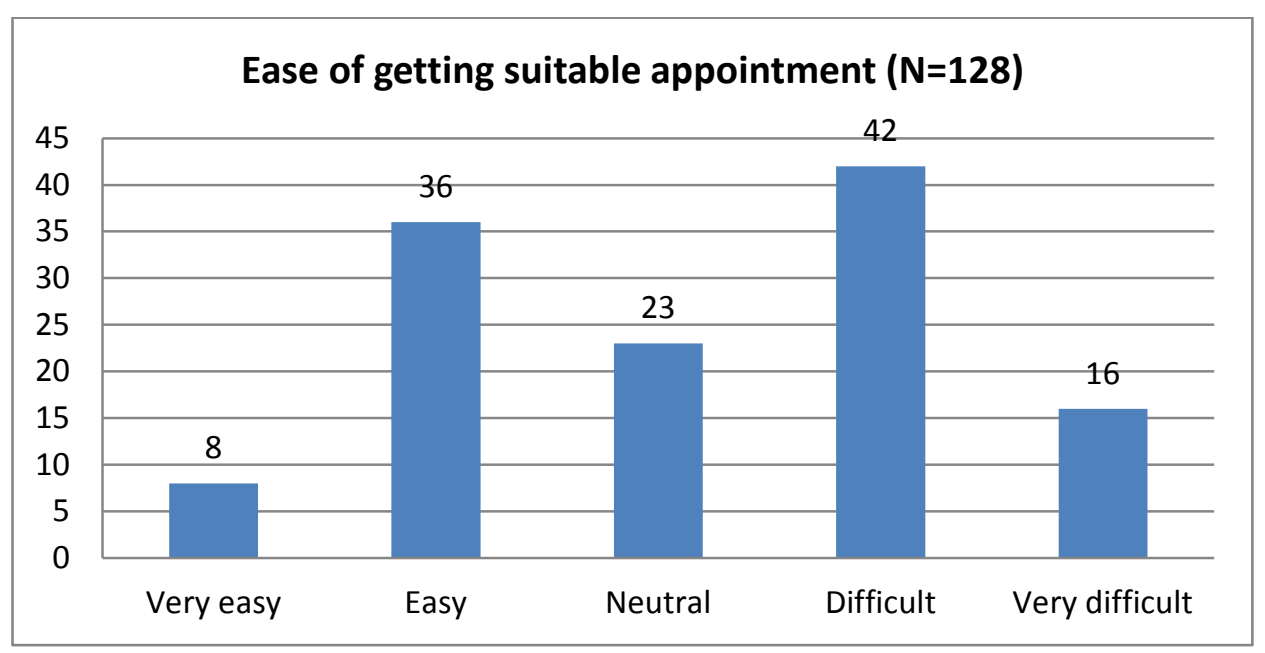

Fig. 3. Survey: Ease of getting a suitable appointment

The survey asked about the ease of getting a suitable appointment time to see a doctor at the local GP practice. As Fig. 3 shows, while 34.4\% considered it either 'very easy' or 'easy', 45.3\% rated it as either 'difficult' or 'very difficult' (18\% were neutral). Common problems were: only being able to book an appointment to see a particular doctor several days or weeks in advance, and trying to get in on the day and possibly getting an appointment time that did not fit in well with their working hours. Table 2 lists the problems in booking an appointment and the frequency that they were mentioned:

Table 2. Comments on appointment booking

\begin{tabular}{|lcllc|}
\hline Comments & $\begin{array}{l}\text { Fre- } \\
\text { quency }\end{array}$ & Comments & $\begin{array}{c}\text { Fre- } \\
\text { quency }\end{array}$ \\
\hline $\begin{array}{l}\text { Can only book on day or several weeks } \\
\text { in advance e.g. to see a specific GP. }\end{array}$ & 17 & It’s OK if you are flexible. & 3 \\
\hline $\begin{array}{l}\text { Generally can get appointment on day or } \\
\text { sometime that week. }\end{array}$ & 10 & Prefer to book online. & 3 \\
\hline $\begin{array}{l}\text { Difficulty finding appointments } \\
\text { fitting in with work or lectures. }\end{array}$ & 8 & $\begin{array}{l}\text { Online OK but easier to line up } \\
\text { and see receptionist. }\end{array}$ & 1 \\
\hline Long waits in surgery to be called. & 5 & $\begin{array}{l}\text { It is easier if receptionist shows } \\
\text { me schedule to choose from. }\end{array}$ & 1 \\
\hline Not enough appointments each day. & 4 & Administration not helpful. & 1 \\
\hline
\end{tabular}




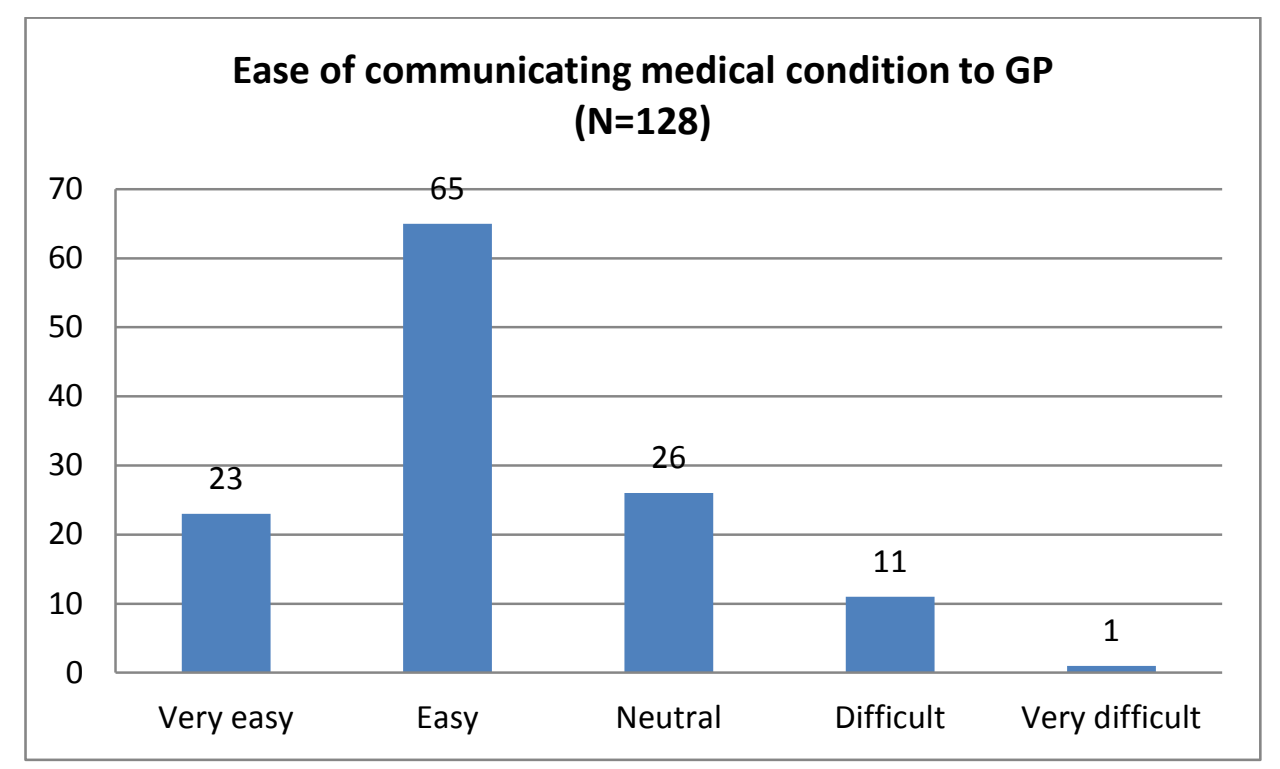

Fig. 4. Survey: Ease of communicating with the doctor

Respondents were asked how easy patients found it to talk to the doctor and to communicate their medical condition to them. As Fig. 4 shows, $68.8 \%$ of the participants stated that communication was either 'easy' or 'very easy'. $9.4 \%$ of the sample experienced more difficulty and felt that patient-doctor communications was either 'difficult' or 'very difficult' (20.3\% were neutral). A number of comments were made that participants found GPs to be very easy to communicate with. One person stated: "I have never had any problems and am satisfied with the advice I have received."

However quite a few participants did highlight communication problems, sometimes due to English not being their first language. Interestingly one comment was: "It is easy to communicate my condition but less easy to receive the advice. I sometimes forget what was said" and "Trying to be really clear about how things feel is difficult - sometimes the words don't seem to cover it". Regarding listening to the doctor's advice, it was said that: "There can be a lot to take in with discussion of symptoms, diagnosis, treatment, next steps, contraindications, etc.", and also: "It is not easy to understand the terminology from doctor. Sometimes I just lack the necessary medical vocabulary.” This might indicate that providing some kind of record for the patient to take away might assist them in understanding their condition better and reduce the need for them to return a make another appointment to seek clarification.

Some participants felt that due to the limitation on appointment times, they felt rushed which restricted their ability to ask questions or to be clear about the advice. It was said that: "The feeling of being rushed and an unclear outcome is also problematic", and also: "I don't think doctors always know what your condition might be or don't want to jump to conclusions too quickly so often tell you to return if symptoms get worse”.

A further problem was that of seeing different doctors (a possible consequence of limited appointment availability) and having to explain their medical history each time. As 
one person said, "Seeing different GPs every time and explaining your medical history and what you've tried before (is a problem)", and the difficulty of "...re-explaining your medical history to a new doctor and showing you have a medical condition".

A key part of the survey was to ask participants whether they would be willing to use a range of methods for seeking medical advice as an alternative to traditional face-toface communication. These included: telephone consultation, email, group session, video-communication and online forum. Fig. 5 shows how many of the respondents would consider using each of these methods.

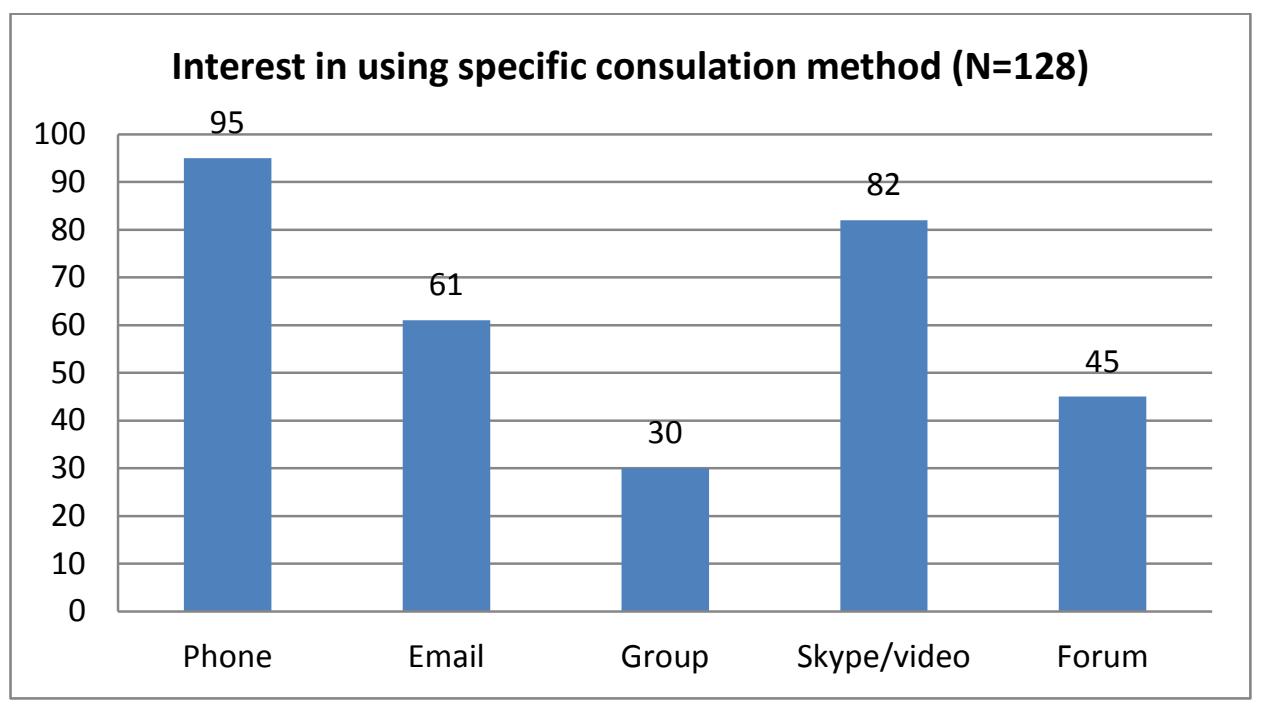

Fig. 5. Survey: Interest in alternative methods of patient-GP consultation

Phone: Telephone consultation with the doctor is a well-established method in the UK. $74.2 \%$ of the respondents said that they would use this method of communication with a doctor and a number confirmed that they had already used it and were happy with it. The clear benefit of the method was that it was: "An easy way to talk to someone professional without having to leave the house". Reservations about telephone consultations were: the difficulty of describing some symptoms over the phone and a concern that they may not be expressed properly. Others said that it would be hard to "Understand what the doctor's saying without a face-to-face chat". However it was thought to be less effective for conditions where the doctor should examine you directly. It was said that a telephone call would be a useful mechanism for: a results review, minor ailments and discussing ongoing or recurring issues. Interestingly one person stated that a telephone call could make the experience less intimidating.

Email: There was less support for the idea of emailing the GP although $47.7 \%$ stated that they would consider using it. A positive comment in favour of it was that the person could: "Think thoroughly about my problem or disease and explain it to them and reply carefully about my answers". However it was also said by one person that it was too impersonal while another said that: "I probably wouldn't trust it as much - might feel that it's automated". One person said that they would: "only use a telephone system with 
a GP who was known to me and I would very carefully explain my condition to avoid misinterpretation". It was also said by one person: "I might have to wait a while for a response and if ill wouldn't want to keep checking my emails". Concern was also expressed that the information might not be confidential. Finally, as for telephone consultations, email would be suitable if: "No physical examination was necessary but could include images to indicate condition/injuries." A service for electronic web-based consultation is eVisits. The authors report on an evaluation of its acceptance and its usability [5].

Group consultation: The idea of meeting as a group to discuss different medical conditions only received support from $23.4 \%$ of participants. There were many reservations about this idea such as: embarrassment at talking or being examined in front of a group, possibly meeting someone they knew at the meeting, lack of confidentiality, and someone might take too much of the time. However for a group who had been diagnosed with a similar condition, a group meeting might be: "beneficial for gathering knowledge for treatment". Group meetings were also thought to be more suitable for discussing chronic conditions. Other comments in favour of the idea were: "This might be good so we can share the experiences and methods" and "Communication is the best way to get more information".

Skype or video consultation: Here the patient would communicate with the doctor through a video link but on a one-to-one basis. This innovation has been tested where a video link has been put into a care home so that residents could seek the doctor's advice without needing to travel to the surgery. Interestingly, $82 \%$ of the participants said that they would be willing to use this method as a means of consultation. A Chi-squared test showed that a significantly higher proportion of those in the 18-29 age group were interested in using video or Skype communication compared to the other two age groups $(p=0.001)$. This is not an unexpected result given the familiarity of the 18-29 age groups with online face-to-face communication. The convenience of a video call was recognised by many participants as well as the advantage of instant feedback and face-to-face communication, making the consultation more personal. One respondent had seen a similar system in use on TV which had given them confidence in using such a system.

Forum: An online forum would be organised by the GP practice for its patients with a doctor moderating the discussion. $45 \%$ of respondents stated that they would use such a service. A positive comment in favour was "I am an online person and surfing a lot to find my answers. This could be a good way to find a solution". It was thought that the forum could be most useful for disseminating general information about medical matters but that the forum would need to be carefully moderated. It was also thought that the event could become confusing if forum members had similar symptoms but different illnesses. The method would be more relevant if the medical condition being discussed was on-going rather than for transient ailments. Examples given of possible online forum topics were: nutrition, high blood pressure or diabetes.

\subsection{Focus group results}

The focus group session was conducted with a group of 5 members of the public aged 50 and over. Within the discussion, a number of problems emerged relating to: patientdoctor communication, patient information, diagnosis, decision making, medication and appointments. These are listed in Table 3 alongside some potential solutions. Some of 
these solutions are related to the different methods of GP consultation studied in the survey:

Table 3. Problems or issues arising from focus group and potential solutions

\section{Problem or issue $\quad$ Potential solution(s)}

Communication: A number of examples of good and poor communication between doctor/GP practice and patient were given. These included: difficulty in communication seriousness of a medical condition, lack of feedback on appointment cancellation, getting blood test results over the phone and being advised that appointment needed.

Complexity of health knowledge: The number of medical conditions and information on treatment that a doctor needs to know about is now so large that it is hard for GPs to keep up to date.

Conflicting views: Sometimes there is a discrepancy between what the doctor diagnoses and what the patient thinks their condition is (based on knowledge of their own body and medical history). This can cause difficulties if the patient doesn't agree with doctor' diagnosis.

Choosing services: Patients are being given more choice about treatment but can find it difficult to choose a medical provider or to judge what treatment to have based on limited information and experience. Sometimes a choice of hospital can be refused if a required specialist doesn't practice in that location or if there is a staff shortage. Travelling a long way for a procedure can be problematic.

Patients being proactive in requesting services: Examples were given where referrals was requested by patients to see a specialist (e.g. physiotherapist, dermatologist). One person decided to pay for their own treatment while another persevered with their surgery and was referred. They found the consultation very helpful.
Providing online systems allowing patients to access summary and routine data about themselves would both save on consultation time and lead to more informed patients who could make better choices about their health and treatment. For minor queries like requesting test results, email or telephone communication could save face to face time with a doctor.

Access to medical specialists by video link in the GP practice or to a decision support system that the doctor and patient jointly interact with could promote higher quality patient-doctor interaction and more accurate diagnoses.

The ability to call upon specialist knowledge either via a support system or video link to a specialist may help to resolve these views. The wider provision of scanning devices in more medical centres would also resolve uncertain diagnosis more quickly.

Social media and inspection reviews have allowed quality ratings to be provided to patients to allow them to make selections of hospital or practitioner but it is recognised that these can be misleading. Having the ability to communicate with the department or consultants before choosing a provider can give patients the information and allow them to make a choice more confidently.

A gradual change is taking place where the patient is becoming a more equal partner in their relationship with the medical profession. Also if online systems improve so that they do not always lead to extreme diagnoses, then patients may be accepted by doctors as better informed and be more willing to accept their views. Patients should be more proactive in requesting medical tests which can lead to earlier diagnosis and more effective treatment. 
Seminars and forums: The idea of a group of local practices organising presentations for patients was well received by the group. It was thought it would be useful to communicate important information to patients e.g. to know whether a child's rash is serious or not and whether they should get medical help. However in the past when a presentation was put on about a medical topic, it wasn't well attended.

Choice of medication: One participant had experience of their normal tablets being swapped for more inexpensive ones but had more side effects resulting in more GP visits about side effects. It was stated that patients need to be assertive and ask for the tablets wanted, rather than change them after a long period of successful use.

Older people's reluctance to visit the doctor: May result in waiting until very poorly before consulting a doctor.

Emergency appointments: If asked whether an emergency appointment is required, it can be hard for the patient to judge. With long waits to see a particular doctor, patients may take emergency appointments when it is not necessary.

Regular appointments: Example given of receptionists being helpful in booking followup with the GP required/preferred.

Waiting times: There was an appreciation that appointment may be delayed if person in front has serious problem. Being prepared to wait is the best strategy.

While efforts are being made to achieve enhanced patient-doctor partnerships, good communication and transparency of process, the results from the focus group show that further improvements are possible.

\section{$4 \quad$ Discussion}

From the results of both studies it can be seen that there is scope to develop new methods to support better patient information and communication with their doctor through a number of different means including:

- Implementing alternative methods of GP contact such as by email or video communication that could fit in better with peoples' preferences, lifestyles and to support those who cannot easily travel to the doctor's surgery. 
- Providing IT systems that give doctors a visual or graphical overview of the surgery's patient population may be helpful. Such systems could highlight those with certain medical conditions who should be contacted when new information or a seminar is being offered. Such a system could also show those patients who have not seen a GP for a period of time and should be considered for being invited in for a check-up.

- Offering new ways for patients to access information about themselves such as directly from the patient record. This service will become more common but there may still be barriers, particularly technical ones, to both patients and clinicians engaging with them [6].

- Providing an application or facility that allows patients to come away from a doctor's consultation within updated information about their condition would encourage them to learn more about their health, be able to discuss it with the doctor on a more informed basis and ultimately take more actions to improve it.

- Offering medical forums moderated by a doctor could help people to learn more about their medical condition by posing questions through the forum and improving their knowledge about it.

\section{$5 \quad$ References}

1. First Annual Digital Health Summit and Exhibition: In collaboration with NHS England and MedeAnalytics, University of Salford, 9 July 2015 http://blogs.salford.ac.uk/onecpd/2015/07/09/round-up-digitalhealth-summit-exhibition-2015

2. VanOsdol, K. J.: Digital Technology to Supercharge Patient-Provider Relationships. Universal Access in Human-Computer Interaction. Aging and Assistive Environments, Volume 8515 of the series Lecture Notes in Computer Science, Springer-Verlag, Berlin, Heidelberg, New York (2014) 415-424

3. Hodge, C.: An evaluation of the user experience of online symptom checkers. Design Ergonomics Final Year dissertation project, Loughborough School of Design, Loughborough University (2015)

4. Bol, N., Scholz, C., Smets, E., Loos, E. F., De Haes, H., Van Weert. J.: Senior Patients Online: which functions should a good patient website offer? Universal Access in Human-Computer Interaction. User and Context Diversity, Volume 8010 of the series Lecture Notes in Computer Science, Springer-Verlag, Berlin, Heidelberg, New York (2013) 32-41

5. Saparova, D., Basic, J., Lu, Y., Kibaru, F., Ma, Y., Yadamsuren, B.: Usability problems in patientand clinician-oriented health information systems: what are they and how do they differ? Digital Human Modelling and Applications in Health, Safety, Ergonomics, and Risk Management. Healthcare and Safety of the Environment and Transport, Volume 8025 of the series Lecture Notes in Computer Science, Springer-Verlag, Berlin, Heidelberg, New York (2013) 276-285

6. Jabour, A. and Jones, J. F.: Facilitators and barriers to patients' engagements with personal health records: systematic review. Universal Access in Human-Computer Interaction. Applications and Services for Quality of Life Volume 8011 of the series Lecture Notes in Computer Science, Springer-Verlag, Berlin, Heidelberg, New York (2013) 472-481 